\title{
Effect of the dispersion of the chromophore on the optical performances of polarizers from polyethylene and 5"-thio- (3-butyl)nonyl-2,2':5',2'"-terthiophene
}

\author{
Andrea Pucci, Letizia Moretto, Giacomo Ruggeri, Francesco Ciardelli * \\ Dipartimento di Chimica e Chimica Industriale, Università di Pisa and INSTM, \\ UdR Pisa, Via Risorgimento 35, 56126 Pisa, Italy; Fax +39050918320; \\ fciard@dcci.unipi.it
}

(Received: February 13, 2002; April 8, 2002)

\begin{abstract}
A new polyethylene-compatible terthiophene chromophore, 5"-thio-(3butyl)nonyl-2,2':5',2"-terthiophene, with melting point lower than $0^{\circ} \mathrm{C}$ was prepared and used for linear polarizers based on ultra-high-molecular-weight polyethylene (UHMWPE). Differential scanning calorimetry and scanning electron microscopy indicate that the new chromophore is dispersed uniformly in films of UHMWPE obtained by casting from solution. The films show excellent dichroic properties (dichroic ratio 30 ) at rather low drawing ratio $(\approx 20)$. Moreover, qualitative agreement is observed with the Ward pseudo-affine deformation scheme.
\end{abstract}

\section{Introduction}

Polymeric host-guest devices are nowadays widely employed due to the advantages obtained by combining the properties of both components. Increasingly important applications of these systems are modern opto-electronic materials formed by host olefin polymers blended with highly conjugated guest polymers, aromatic or inorganic molecules [1]. In addition, chain orientation and extension of the host polymer system can also be used to generate and to enhance for instance the optical [2], electrical [3] and thermal [4] properties of the binary devices.

Studies of the dispersion of the guest in the host polymeric phase have shown that the presence of phase-separated regions inside the device due to the tendency of the guest molecules to aggregate may yield materials with poor mechanical [4], electronic and optical [5] properties. In particular the dispersion of organic dichroic guest molecules in polyethylene was shown to affect the optical properties of linear absorbing polarizers [6,7] due to the heterogeneity related to the immobilization of the dispersed guest molecule during tensile deformation of the host polyethylene matrix. Modification of the blending process and use of processable polyethylenes with different molecular weight and density allowed to improve the homogeneity of the host-guest system, leading to materials with better optical performances $[8,9]$. The structure of a guest molecule with crystallization tendency does not allow to prepare homogeneous devices due to the formation of molecular aggregates.

In the present paper we compare the dispersion mechanism of a new terthiophenebased molecule functionalized with a branched lateral alkyl chain (1) in a ultra-high- 
molecular-weight polyethylene matrix with that of a similar absorbing molecule with a linear alkyl chain (2) characterized by high crystallization capacity. The dispersion behaviour of the two chromophores and the properties of the films prepared by solution-casting were evaluated by differential scanning calorimetry (DSC), scanning electronic microscopy (SEM) and UV-vis spectroscopy in polarized light.

\section{Results and discussion}

\section{Chromophore synthesis}

In order to obtain a better understanding of the dispersion mechanism of organic molecules in polyethylene matrices, a new heteroaromatic chromophore was synthesized by functionalizing the conjugated terthiophene nuclei, subject of previous studies [6], either with a linear or a branched alkyl chain having 18 and 13 carbon atoms, respectively (Fig. 1). Terthiophene was prepared according to a literature procedure [10], using palladium catalyst to couple mono- and disubstituted thiophene derivatives. The heteroaromatic core was then functionalized with different thioethers: (a) a linear $\mathrm{C}_{18}$ commercial thioether, as reported in a previous work [6]; (b) a branched thioether synthesized in 4 steps starting from a $\mathrm{C}_{9}$ linear $\alpha, \beta$-unsaturated aldehyde that reacts then with a dialkylcopper cyanide $\left(\mathrm{C}_{4}\right)$ with a Michael type mechanism as reported in the synthetic path in Fig. 2.

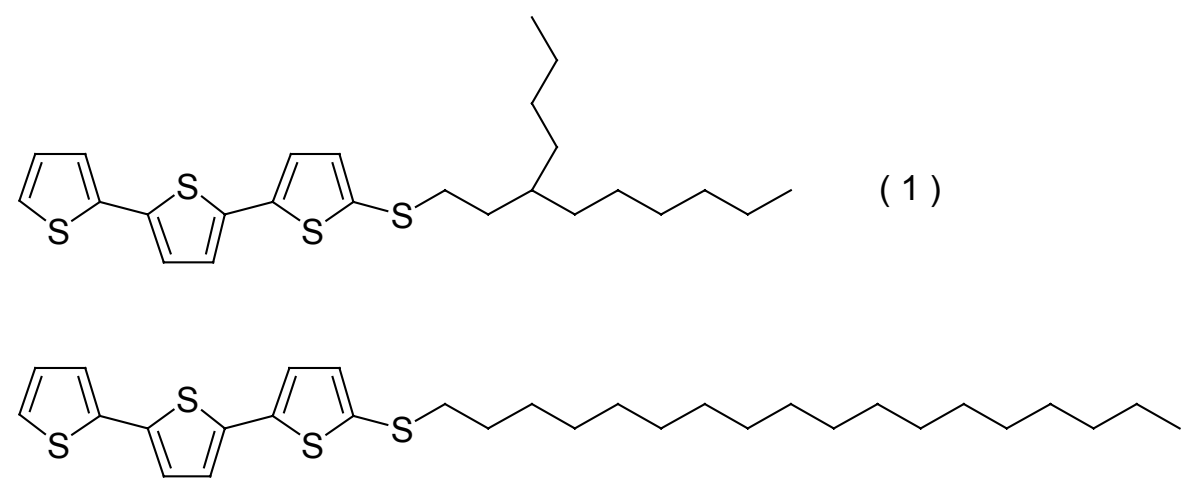

Fig. 1. 5"-Thio-(3-butyl)nonyl-2,2':5',2"-terthiophene (1) and 5"-thiooctadecyl$2,2^{\prime}: 5$ ',2"-terthiophene (2)

The identical UV-vis absorption spectra of dioxane solutions of the two chromophores (Fig. 3) indicate that the dipole moment of terthiophene is not influenced by the structure of the lateral alkyl chain.

The introduction of different lateral alkyl chains on the terthiophene core modifies the thermal behaviour. Indeed the first heating of the DSC traces (Fig. 4) show that the linear aliphatic $\mathrm{C}_{18}$ chain gives rise to a chromophore with high crystallinity and melting point $\left(\mathrm{T}_{\mathrm{m}}=82 / 91^{\circ} \mathrm{C}, \Delta \mathrm{H}_{\mathrm{f}}=122.3 \mathrm{~J} / \mathrm{g}\right)$, whereas the branched one leads to a liquid molecule at room temperature $\left(\mathrm{T}_{\mathrm{m}}=-5.6^{\circ} \mathrm{C}, \Delta \mathrm{H}_{\mathrm{f}}=21.4 \mathrm{~J} / \mathrm{g}\right)$. 


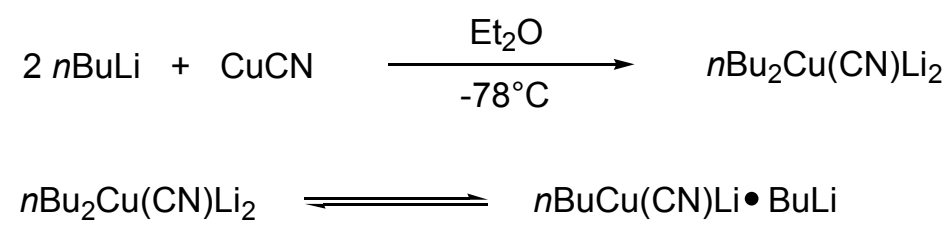<smiles>CCCCCCC(CCO)CCCC</smiles><smiles>c1csc(-c2ccc(-c3cccs3)s2)c1</smiles>

Fig. 2. Synthetic path followed in the dyes preparation

Film preparation and characterization

The polymeric films were prepared [6,7] by casting from hot xylene solution a mixture of UHMWPE and chromophore, $\mathbf{1}$ or $\mathbf{2}$, respectively, in a concentration either $3 \%$ or $10 \%$ by weight with respect to the host polymer (Tab. 1).

The homogeneity of the prepared binary films was investigated by SEM. The SEM micrographs of the film based on UHMWPE and 2 with the larger concentration, UHMWPE2-10, revealed a large-scale heterogeneity (Fig. 5a). In particular the sulfur concentration profile determined by X-ray microanalysis of a section of the same film (Fig. 5b) showed a chromophore concentration peak at the film surface [6]. 


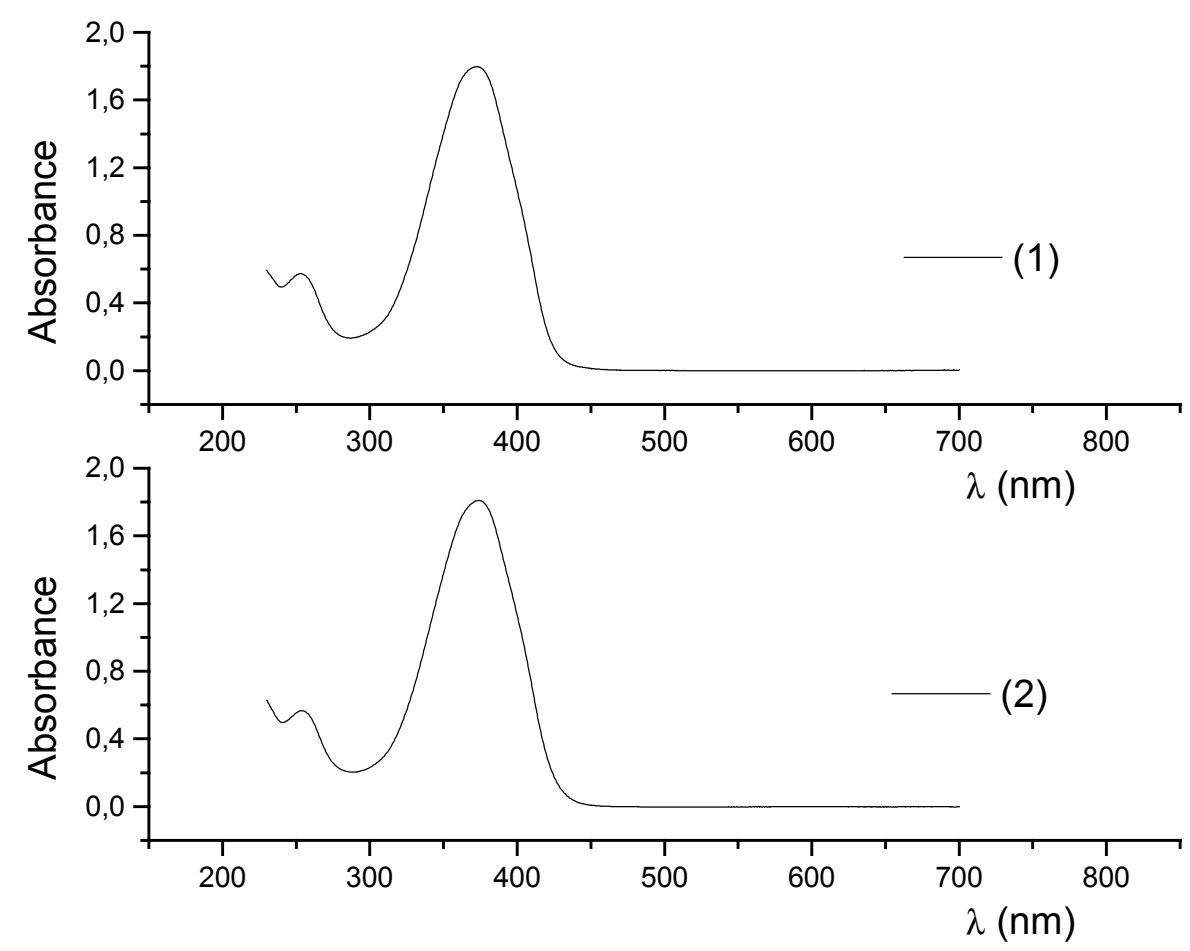

Fig. 3. UV-vis spectra of $5 \cdot 10^{-5} \mathrm{M}$ dioxane solutions of $\mathbf{1}$ and $\mathbf{2}$

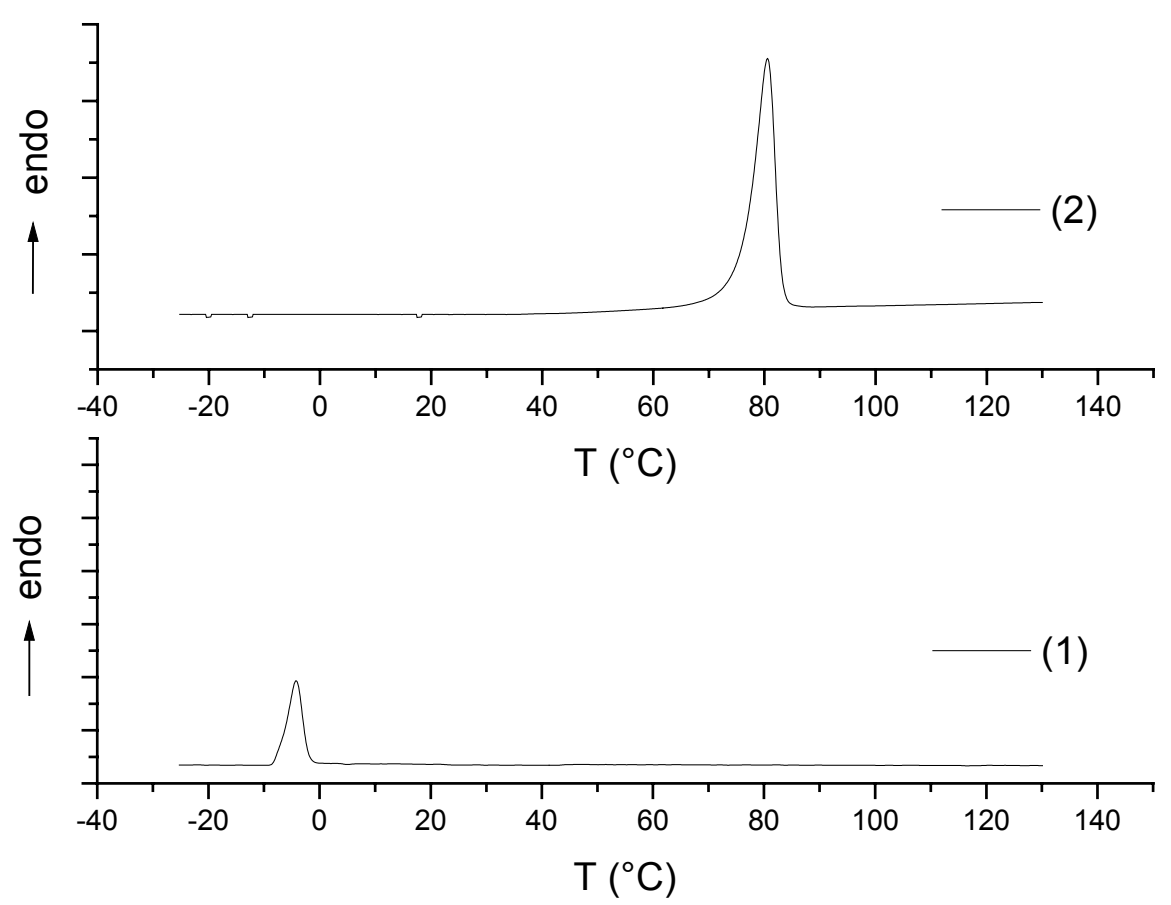

Fig. 4. First-heating DSC traces of 1 and 2 
Tab. 1. Composition of the binary films prepared

\begin{tabular}{ccc}
\hline Sample & Chromophore & $\begin{array}{c}\text { Concentration } \\
\text { in wt.-\% }\end{array}$ \\
\hline \hline UHMWPE1-3 & $\mathbf{1}$ & 3 \\
UHMWPE1-10 & $\mathbf{1}$ & 10 \\
UHMWPE2-3 & $\mathbf{2}$ & 3 \\
UHMWPE2-10 & $\mathbf{2}$ & 10 \\
\hline
\end{tabular}
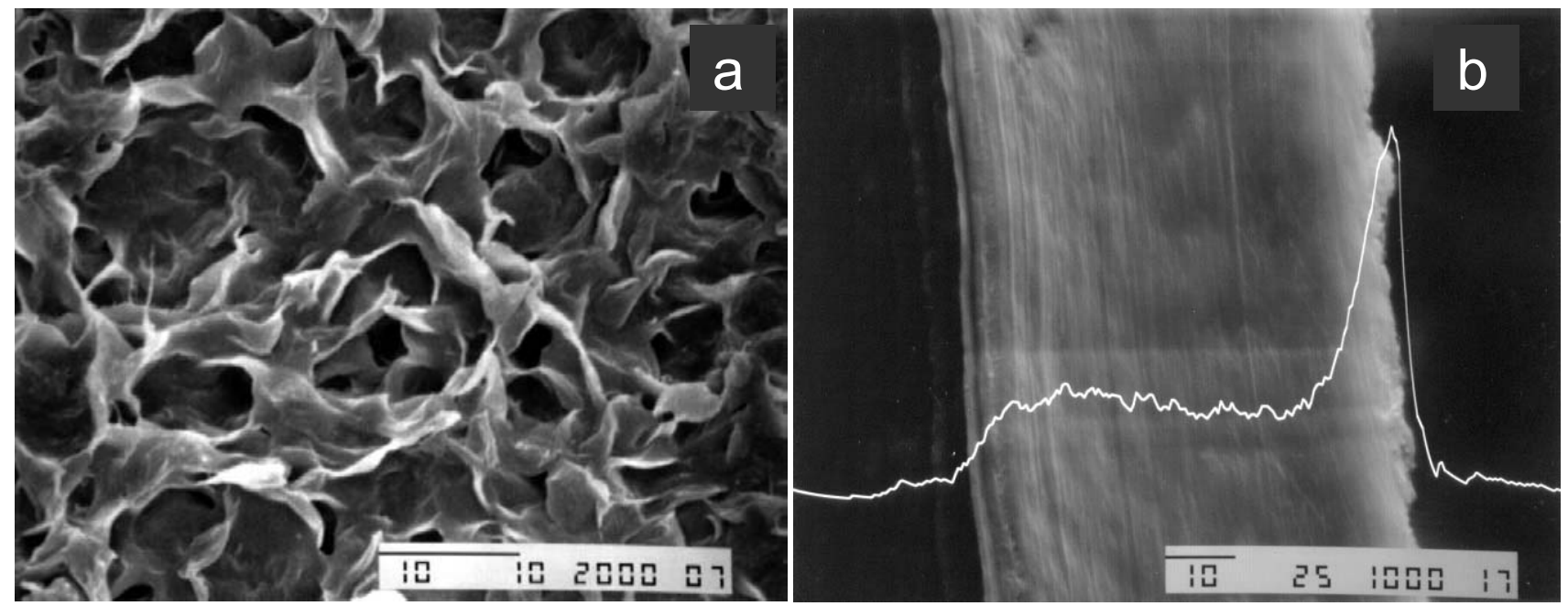

Fig. 5. Scanning electron micrograph (a) and sulfur concentration profile (b) of a 3 wt.-\% 2/UHMWPE film before orientation
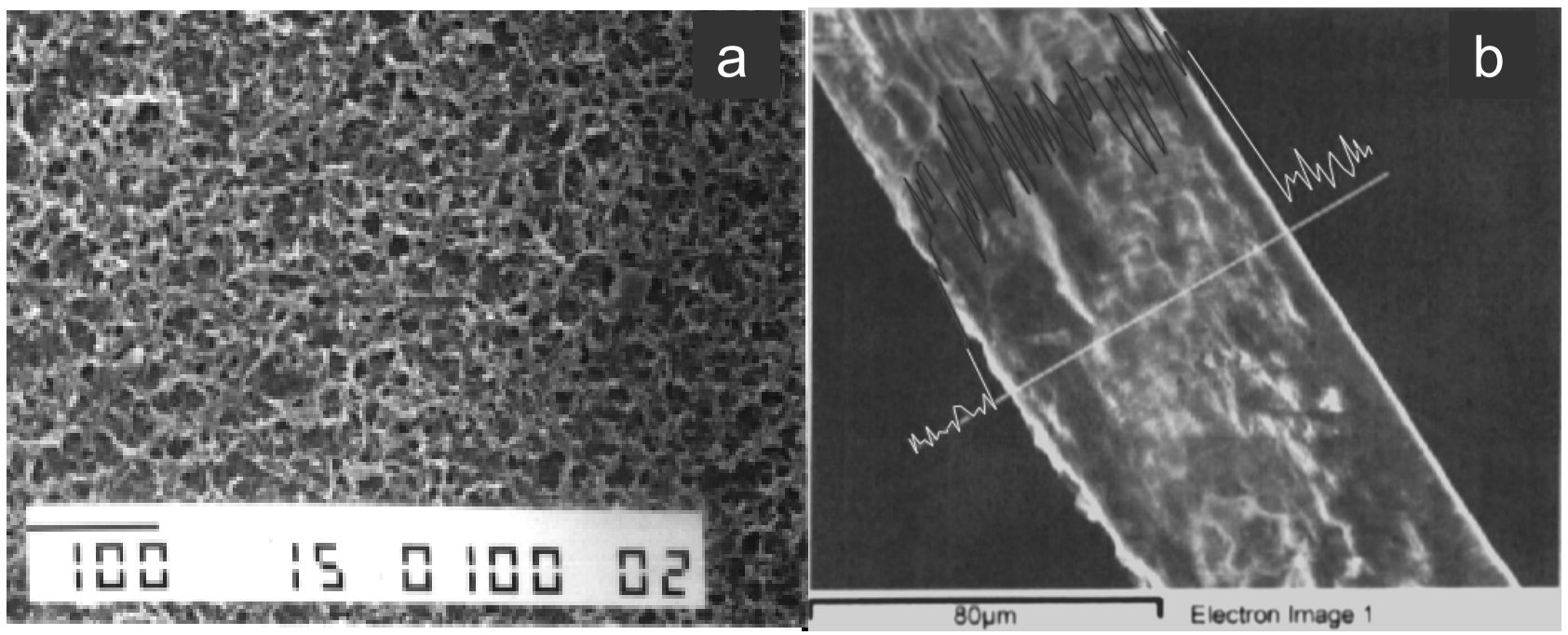

Fig. 6. Scanning electron micrograph (a) and sulfur concentration profile (b) of a 3 wt.-\% 1/UHMWPE film before orientation 
The scanning electron microscopy image (Fig. 6a) of the film based on UHMWPE and the branched chromophore 1, UHMWPE1-10, reveals an improved dispersion of the guest polar dye within the polymeric matrix (Fig. 6b), with uniform distribution along the section of the film.

Moreover the melting peak of chromophore 1 was not detectable, whereas the DSC trace of the UHMWPE2-10 film showed the melting peak of the guest phase (2) located at the same temperature as for the pure chromophore $\left(82 / 91^{\circ} \mathrm{C}\right)$ (Fig. 7a). This indicates that the dispersion of the terthiophene functionalized with a long linear alkyl chain (2) is only partial due to its high tendency to separate crystallization [7].
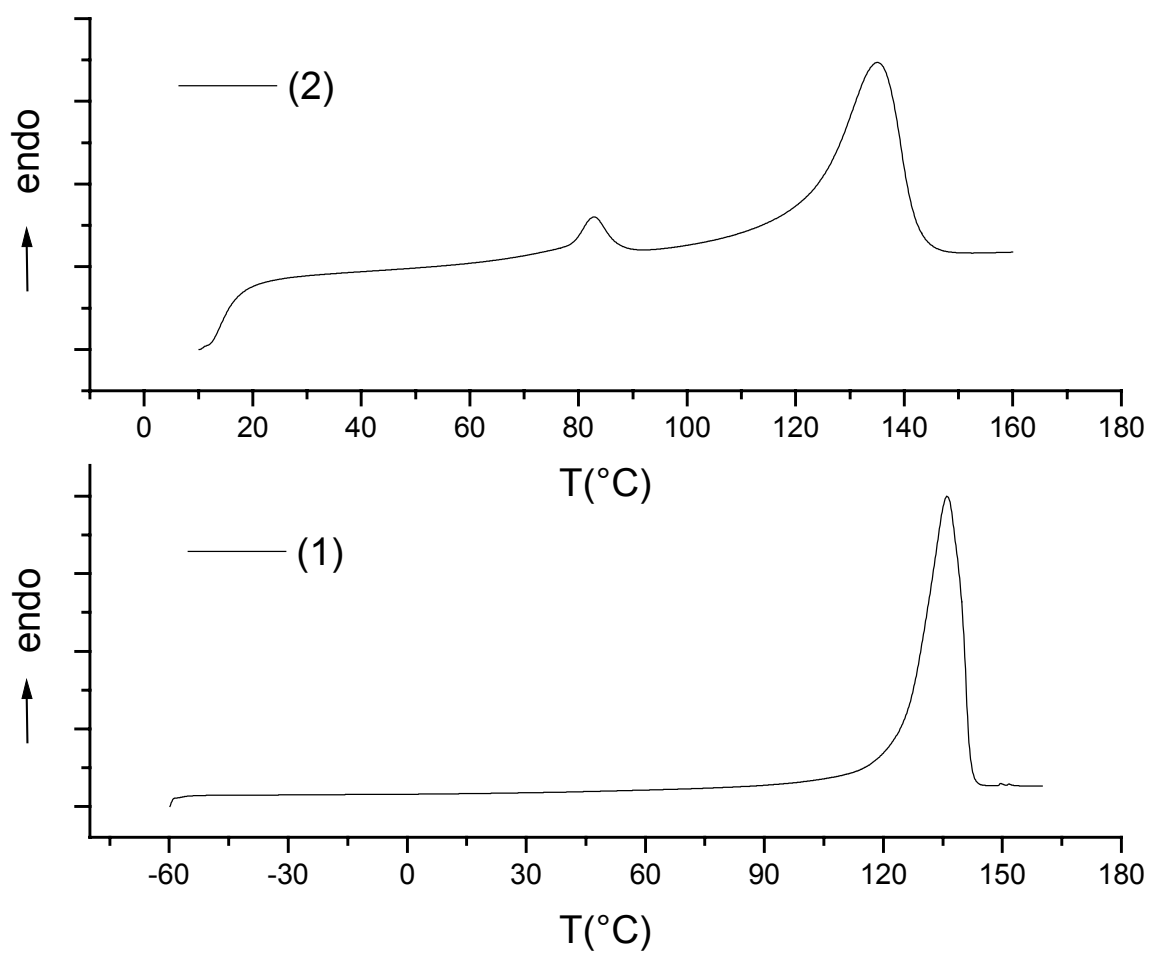

Fig. 7. First-heating DSC traces of 3 wt.- $\%$ of dye/UHMWPE films

The presence of crystalline aggregates of chromophore is probably responsible for defects in the crystalline structure of the polyethylene matrix leading to a lower melting point $\left(135^{\circ} \mathrm{C}\right.$ instead of $\left.141^{\circ} \mathrm{C}\right)[7]$ (Fig. $\left.7 \mathrm{~b}\right)$.

Uniaxial orientation of the host-guest films was performed by stretching at a temperature $\left(T \leq 135^{\circ} \mathrm{C}\right)$ close to, but lower than, the melting temperature of the polymer. The orientation behaviour of both components of the tensile deformed films can be qualitatively described by the theoretical pseudo-affine deformation scheme based on the aggregate model originally proposed by Ward [11-13] assuming that the dichroic guest molecules adopt the orientation of the polymeric matrix in which they are dispersed.

UV-vis spectroscopy analyses have recently demonstrated that not oriented hostguest films characterized by a high degree of phase separation between its components generate after tensile deformation polymeric films that do not follow the theoretical pseudo-affine scheme and are characterized by a modest dichroism $[5,6]$. 
The effect of the increased dispersion of the branched chromophore 1 in polyethylene on the optical performances is confirmed by the comparative UV-vis spectroscopy analysis in polarized light of the oriented UHMWPE1-3 and UHMWPE2-3 films containing 3 wt.- $\%$ of the dichroic molecules 1 and 2 , respectively.

The transmissions parallel $\left(T_{/ I}\right)$ and perpendicular $\left(T_{\perp}\right)$ to the orientation direction were calculated $\left(T=10^{-A}\right)$ from the absorbances parallel $\left(A_{/ /}\right)$and perpendicular $\left(A_{\perp}\right)$ to the drawing direction. The optical polarizing properties and performances were then evaluated by calculating the dichroic ratio $(R)$, the order parameter $(S)$, the polarization efficiency (PE) and the single piece transmittance [15].

$$
\begin{aligned}
& \mathrm{R}=\mathrm{A}_{/ /} / \mathrm{A}_{\perp} \\
& \mathrm{S}=(\mathrm{R}-1) /(\mathrm{R}+2) \\
& \mathrm{PE}=\left(\mathrm{T}_{\perp}-\mathrm{T}_{/ /}\right) /\left(\mathrm{T}_{\perp}+\mathrm{T}_{/ /}\right) \\
& \mathrm{T}_{\mathrm{sp}}=\left(\mathrm{T}_{\perp}+\mathrm{T}_{/ /} / 2\right.
\end{aligned}
$$

A summary of the optical properties presented by the prepared devices is shown in Tab. 2.

Tab. 2. Dichroic and polarizer parameters of the $3 \mathrm{wt} . \mathrm{\%}$ mixture of $\mathbf{1}$ and $\mathbf{2}$ in UHMWPE at various drawing ratios

\begin{tabular}{cccccc}
\hline Sample & $\begin{array}{c}\text { Drawing } \\
\text { ratio }\end{array}$ & $\mathrm{R}$ & $\mathrm{S}$ & $\mathrm{PE}$ & $\mathrm{T}_{\mathrm{sp}}$ \\
\hline \hline UHMWPE2-3 & 20 & 2.4 & 0.32 & 0.24 & 0.56 \\
& 30 & 7 & 0.67 & 0.41 & 0.61 \\
& 40 & 17.4 & 0.85 & 0.25 & 0.77 \\
UHMWPE1-3 & 20 & 31.1 & 0.91 & 0.43 & 0.68 \\
& 30 & 11 & 0.77 & 0.24 & 0.76 \\
& 40 & 2.5 & 0.33 & 0.12 & 0.75 \\
\hline
\end{tabular}

The oriented films obtained by stretching of UHMWPE1-3 and UHMWPE2-3 presented an opposite behaviour in terms of the optical properties and the dichroic dye orientation. In particular the film containing the branched $\mathbf{1}$ showed at low stretching ratio (20) high orientation of the chromophore along the polyethylene fibres $(\mathrm{R}>30)$ (Fig. 8a) and optical performances very close to the pseudo-affine deformation scheme (Fig. 8b). These findings can be attributed to the good dispersion of the dye in the polyethylene matrix.

Increasing the drawing ratio, the orientation of chromophore 1 decreases with deviation from the pseudo affine scheme. This last behaviour can be probably attributed to the branched alkyl substituent of the chromophore which hampers the orientation of the dye along the crystalline fibres of the polymer during tensile deformation due to the progressive ejection of $\mathbf{1}$ from the crystalline phase to the amorphous phase $[16,17]$. 

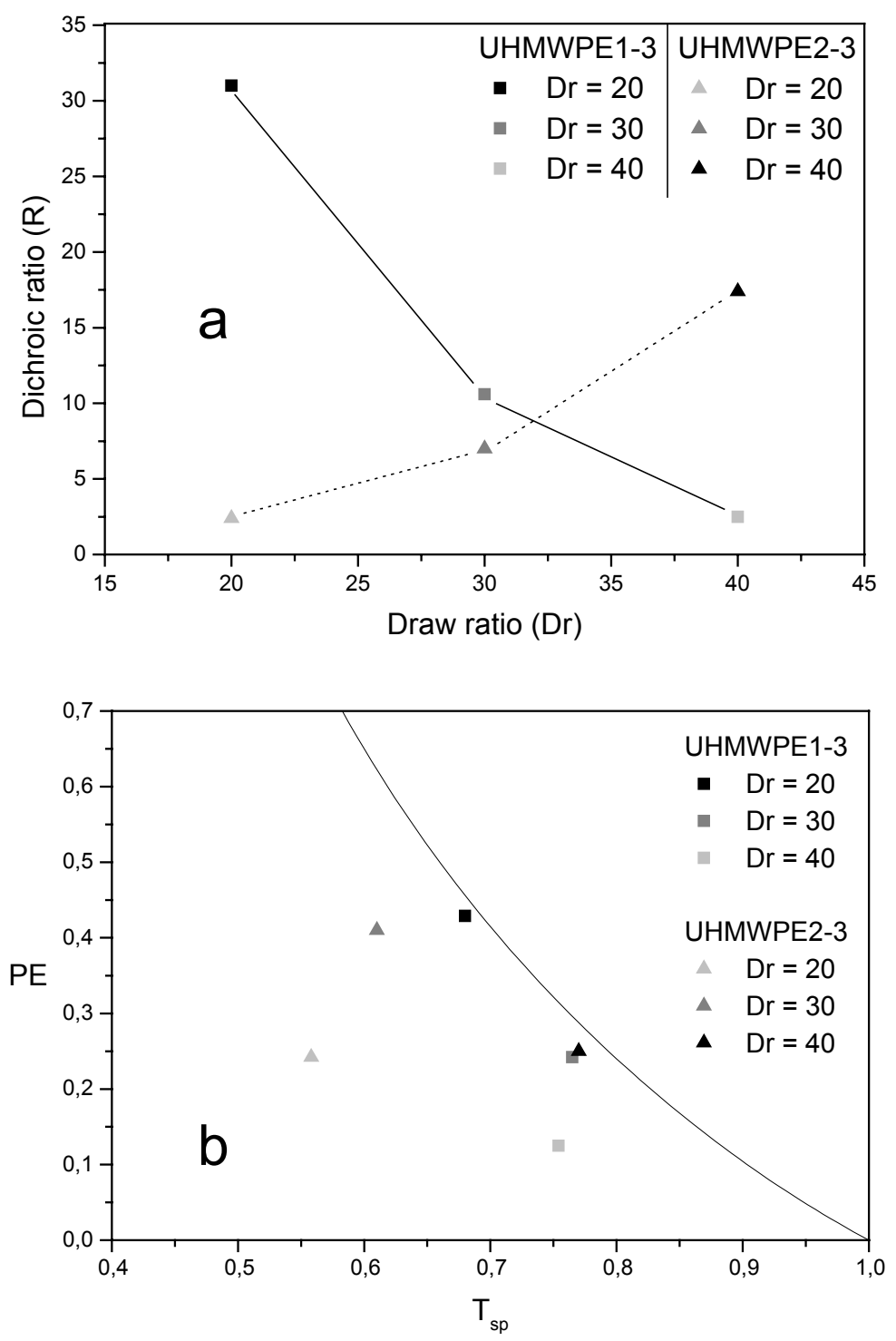

Fig. 8. Orientation of the chromophores (a) and performance of the polarizers (b) of all oriented blends

An opposite behaviour was found for the film containing the linear chromophore 2 having dichroic ratio and polarizer performances, respectively, very low and far from the theoretical pseudo-affine deformation scheme at low stretching ratio (20-30). With increasing the tensile deformation these values become higher and very similar to the theoretical behaviour, probably due to a better dispersion of the chromophore in the polymeric matrix with increasing drawing ratio [6].

\section{Conclusion}

A highly dichroic chromophore with very low tendency to crystallize $\left(T_{m}=-5^{\circ} \mathrm{C}\right)$ was prepared. This was achieved by replacing with a branched chain the linear alkyl chain, present in previously studied chromophores to favour miscibility with polyethylene. As proposed in previous papers it is here confirmed that the crystallinity of the chromophore plays a fundamental role in controlling the thermodynamics of mixing $[6,9]$. The branched chromophore can then be dispersed uniformly at mole- 
cular level in UHMWPE thus providing polarizers with high dichroic ratio which fit the Ward law.

Interestingly the maximum $\mathrm{R}$ is obtained at a stretching ratio (Dr) of only 20 , whereas the linear chromophore at $\mathrm{Dr}$ as high as 40 shows lower performances. This last results suggest the convenient use of conventional less stretchable but more easily processable ethylene polymer as the matrix, thus allowing easier preparation of the binary film by mechanical mixing.

\section{Experimental part}

\section{Materials}

Reagents and solvents were commercial products from Aldrich Chemical Co., Fluka, and Carlo Erba. UHMWPE with $\mathrm{Mw}=3.6 \cdot 10^{6} \mathrm{~g} / \mathrm{mol}$, UH210, was obtained from DSM. Spectroscopic grade dioxane (Aldrich) was used for the absorption experiments. Diethyl ether was refluxed on $\mathrm{Na}$ for $6 \mathrm{~h}$ before distillation. Tetrahydrofuran (THF) was stored over $\mathrm{KOH}$ pellets for one hour, then refluxed on $\mathrm{LiAlH}_{4}$ for $6 \mathrm{~h}$ and finally distilled. $\mathrm{PBr}_{3}$ was distilled under nitrogen atmosphere. Pyridine was refluxed for $6 \mathrm{~h}$ over $\mathrm{KOH}$ pellets and then distilled. 3-Butyl-nonanal was distilled under nitrogen atmosphere.

\section{Methods}

${ }^{1} \mathrm{H}$ and ${ }^{13} \mathrm{C}$ NMR spectra were recorded with a Varian Gemini-200 $\mathrm{MHz}$ spectrometer on 5-10 wt.-\% $\mathrm{CDCl}_{3}$ solutions.

FT-IR spectra were recorded with a Perkin Elmer 1330 spectrometer on films casted on $\mathrm{KBr}$ windows or on dispersions in $\mathrm{KBr}$.

UV-VIS spectra were recorded in dioxane solutions $\left(5 \cdot 10^{-5} \mathrm{M}\right)$ or on polymer films (in polarized light, Sterling Optics UV linear polarizer film deposed on a quartz plate) with a Jasco 7850 UV-VIS spectrophotometer.

Mass spectra were recorded with a Varian Saturn 2000 connected to a gas-chromatograph Varian 3800, on solutions of diethyl ether.

The melting points and the optical microscopic analysis were accomplished with a Reichert Polyvar optical microscope with crossed polarizers, equipped with a programmable Mettler FP 52 hot stage.

Scanning Electron Microscopy (SEM) analysis was performed with a Jeol 5600-LV microscope, equipped with Oxford X-rays EDS microprobe, at the Chemical Engineering Department of Pisa University.

Differential scanning calorimetry (DSC) measurements were carried out with a Perkin-Elmer DSC7 calorimeter equipped with a CCA7 cooling device. Mercury (m.p. $=-38.4^{\circ} \mathrm{C}$ ) and indium (m.p. $=156.2^{\circ} \mathrm{C}$ ) standards for low temperature scans have been used for instrument calibration. Heating and cooling thermograms were measured at a scan rate of $10^{\circ} \mathrm{C} / \mathrm{min}$.

Flash Chromatography was carried out with a Biotage ZIF-SIM FLASH ${ }^{\mathrm{TM}}$ chromatograph. 


\section{Film preparation}

$0.5 \mathrm{~g}$ of UHMWPE and the appropriate quantities of chromophore were dissolved in $75 \mathrm{~mL}$ of $p$-xylene at $125^{\circ} \mathrm{C}$ and stirred until complete dissolution occurred; the solution was then cast on a cold glass and the solvent allowed to evaporate slowly. The polymeric films were manually drawn on a "hot shoe" at $135^{\circ} \mathrm{C}$. The draw ratio (Dr) was determined by measuring the displacement of the ink marks printed upon the polymeric film. The film roughness was diminished using ultra-pure silicon oil to reduce surface scattering between the films and the quartz slides used to keep them planar. In the analysis of the absorption data, the scattering contribution was corrected by the use of appropriate baselines. The fitting procedure was performed by using Origin 5.0 , software by Microcal Origin ${ }^{\circledR}$.

\section{3-Butylnonanal}

$6.18 \mathrm{~g}(69 \mathrm{mmol})$ of $\mathrm{CuCN}$ are dissolved in $69 \mathrm{~mL}$ of dry diethyl ether under dry nitrogen atmosphere. At $-78^{\circ} \mathrm{C}$ (methanol/liquid nitrogen bath) $86.3 \mathrm{~mL}$ of $n$-butyllithium (1.6 $\mathrm{M}$ hexane solution) was added to the mixture. The temperature was gently allowed to rise until $0^{\circ} \mathrm{C}$ for $5 \mathrm{~min}$, and after all the $\mathrm{CuCN}$ was dissolved, the system was cooled to $-78^{\circ} \mathrm{C}$ and $8 \mathrm{~mL}$ of trans-2-nonenal $(48.3 \mathrm{mmol})$ was added. After stirring for $1 \mathrm{~h}$ at $-78^{\circ} \mathrm{C}$ the reaction mixture was quenched with a $10 \%$ solution of $\mathrm{NH}_{4} \mathrm{Cl} / \mathrm{NH}_{4} \mathrm{OH}$, extracted with diethyl ether and dried over $\mathrm{Na}_{2} \mathrm{SO}_{4}$. After solvent evaporation, the product was purified by flash chromatography on silica gel using pentane/diethyl ether $9: 1$ as eluent. $6.66 \mathrm{~g}(33 \mathrm{mmol}$, yield $70 \%)$ of a viscous pale yellow liquid was recovered.

${ }^{1} \mathrm{H}$ NMR $\left(\mathrm{CDCl}_{3}\right): \delta=0.8-0.9\left(\mathrm{~m}, 6 \mathrm{H}, \mathrm{CH}_{3}\right) ; 1.2-1.6\left(\mathrm{~m}, 16 \mathrm{H},-\mathrm{CH}_{2^{-}}\right) ; 1.8(\mathrm{~m}, 1 \mathrm{H}$, $\left.\mathrm{CHCH}_{2} \mathrm{CHO}\right) ; 2.3\left(\mathrm{~m}, 2 \mathrm{H}, \mathrm{CH}_{2} \mathrm{CHO}\right) ; 9.7$ (t, $\left.1 \mathrm{H},-\mathrm{CHO}, \mathrm{J}=2 \mathrm{~Hz}\right) \mathrm{ppm}$.

${ }^{13} \mathrm{C} \mathrm{NMR}\left(\mathrm{CDCl}_{3}\right): \delta=13.7-13.9\left(\mathrm{CH}_{3}\right) ; 22.6-38.6\left(-\mathrm{CH}_{2-}\right) ; 48.4(\mathrm{CH}) ; 178.9(\mathrm{CHO})$ ppm.

FT-IR: $736\left(\rho \mathrm{CH}_{2}\right), 1378\left(\delta_{\mathrm{s}} \mathrm{CH}_{3}\right), 1466\left(\delta_{\mathrm{s}} \mathrm{CH}_{2}\right), 1726$ ( $\left.\nu \mathrm{CO}\right), 2716$ ( $\nu \mathrm{C}-\mathrm{H}$ ald.), $2858\left(\nu_{\mathrm{s}} \mathrm{CH}_{2}\right), 2928\left(\nu_{\text {as }} \mathrm{CH}_{2}\right), 2966\left(\nu_{\text {as }} \mathrm{CH}_{3}\right) \mathrm{cm}^{-1}$.

Mass spectrometry: m/z = $199(\mathrm{M}+1), 198(\mathrm{M}), 154(\mathrm{M}-44), 141(\mathrm{M}-57)$.

\section{3-Butylnonanol}

$0.36 \mathrm{~g}(9.4 \mathrm{mmol})$ of $\mathrm{LiAlH}_{4}$ was dissolved in $12 \mathrm{~mL}$ of dry diethyl ether under dry nitrogen atmosphere. $6.66 \mathrm{~g}$ (33 mmol) of 3-butylnonanal dissolved in $8 \mathrm{~mL}$ of dry diethyl ether was slowly dropped to the solution and the system was then refluxed with stirring. After $1 \mathrm{~h}$ the reaction was quenched at room temperature with $10 \%$ $\mathrm{H}_{2} \mathrm{SO}_{4}$, extracted with diethyl ether and dried over $\mathrm{Na}_{2} \mathrm{SO}_{4}$. After solvent evaporation, the product was purified by chromatography on silica gel using pentane/diethyl ether 9:1 to remove the unreacted aldehyde and ethyl acetate as eluents. $5.61 \mathrm{~g}(28 \mathrm{mmol}$, yield $80 \%$ ) of a viscous pale yellow liquid was recovered.

${ }^{1} \mathrm{H}$ NMR $\left(\mathrm{CDCl}_{3}\right): \delta=0.8-0.9\left(\mathrm{~m}, 6 \mathrm{H}, \mathrm{CH}_{3}\right) ; 1.1-1.3\left(\mathrm{~m}, 16 \mathrm{H},-\mathrm{CH}_{2^{-}}\right) ; 1.5(\mathrm{~m}, 2 \mathrm{H}$, $\left.\mathrm{CH}_{2} \mathrm{CH}_{2} \mathrm{OH}, J=7 \mathrm{~Hz}\right) ; 1.6\left(\mathrm{~m}, 1 \mathrm{H}, \mathrm{CHCH}_{2} \mathrm{CH}_{2} \mathrm{OH}\right) ; 3.7\left(\mathrm{t}, 2 \mathrm{H},-\mathrm{CH}_{2} \mathrm{OH}, J=7 \mathrm{~Hz}\right)$ ppm.

${ }^{13} \mathrm{C}$ NMR $\left(\mathrm{CDCl}_{3}\right): \delta=14.1\left(\mathrm{CH}_{3}\right) ; 22.9-34.3\left(-\mathrm{CH}_{2}-\right) ; 37.1\left(\mathrm{CH} 2 \mathrm{CH}_{2} \mathrm{OH}\right) ; 61\left(\mathrm{CH}_{2} \mathrm{OH}\right)$ ppm. 
FT-IR: $726\left(\rho \mathrm{CH}_{2}\right), 1058(\nu \mathrm{C}-\mathrm{OH}), 1378\left(\delta_{\mathrm{s}} \mathrm{CH}_{3}\right), 1466\left(\delta_{\mathrm{s}} \mathrm{CH}_{2}\right), 2858\left(\nu_{\mathrm{s}} \mathrm{CH}_{2}\right)$, $2926\left(\nu_{\text {as }} \mathrm{CH}_{2}\right), 2956\left(\nu_{\text {as }} \mathrm{CH}_{3}\right), 3334(\nu \mathrm{O}-\mathrm{H}) \mathrm{cm}^{-1}$.

Mass spectrometry: m/z = $200(\mathrm{M}), 199(\mathrm{M}-1), 154(\mathrm{M}-46)$.

\section{5-(2-Bromoethyl)undecane}

$5.61 \mathrm{~g}(28 \mathrm{mmol})$ of 3-butylnonanol were dissolved in $10 \mathrm{~mL}$ of pyridine under dry nitrogen atmosphere. At $-10^{\circ} \mathrm{C}, 1.3 \mathrm{~mL}$ (14 mmol) of $\mathrm{PBr}_{3}$ was slowly dropped to the solution and the reaction mixture was stirred at room temperature for $4 \mathrm{~h}$. The mixture was then quenched with ice and water, neutralized with a saturated solution of $\mathrm{NaHCO}_{3}$, extracted with diethyl ether and dried over $\mathrm{Na}_{2} \mathrm{SO}_{4}$ for a night. After solvent evaporation, the product was purified by chromatography on silica gel using $n$-hexane/ethyl acetate 9:1 as eluent. $4.99 \mathrm{~g} \mathrm{(19} \mathrm{mmol,} \mathrm{yield} \mathrm{67 \% )} \mathrm{of} \mathrm{a} \mathrm{viscous} \mathrm{liquid}$ was recovered.

${ }^{1} \mathrm{H}$ NMR $\left(\mathrm{CDCl}_{3}\right): \delta=0.8-0.9\left(\mathrm{~m}, 6 \mathrm{H}, \mathrm{CH}_{3}\right) ; 1.1-1.3\left(\mathrm{~m}, 16 \mathrm{H},-\mathrm{CH}_{2}\right) ; 1.6(\mathrm{~m}, 1 \mathrm{H}, \mathrm{CH})$; $1.9\left(\mathrm{~m}, 2 \mathrm{H}, \mathrm{CH}_{2} \mathrm{CH}_{2} \mathrm{Br}\right.$ ); 3.4 (t, $2 \mathrm{H},-\mathrm{CH}_{2} \mathrm{Br}$ ) ppm.

${ }^{13} \mathrm{C} \mathrm{NMR}\left(\mathrm{CDCl}_{3}\right): \delta=14.1\left(\mathrm{CH}_{3}\right) ; 22.7-36.5\left(-\mathrm{CH}_{2}-\right) ; 37.3\left(\mathrm{CH}_{2} \mathrm{Br}\right) \mathrm{ppm}$.

FT-IR: $726\left(\rho \mathrm{CH}_{2}\right), 1258(\omega \mathrm{C}-\mathrm{Br}), 1378\left(\delta_{\mathrm{s}} \mathrm{CH}_{3}\right), 1464\left(\delta_{\mathrm{s}} \mathrm{CH}_{2}\right), 2856\left(v_{\mathrm{s}} \mathrm{CH}_{2}\right)$, $2926\left(\nu_{\text {as }} \mathrm{CH}_{2}\right), 2956\left(\nu_{\text {as }} \mathrm{CH}_{3}\right) \mathrm{cm}^{-1}$.

Mass spectrometry: $\mathrm{m} / \mathrm{z}=221,219$ (M-43), 209, 207 (M-55), 193, 191 (M-71), 167, 165 (M-97).

\section{5"-Thio-(3-butyl)nonyl-2,2':5',2"-terthiophene (1)}

$5.42 \mathrm{~g}$ (21.8 mmol) of 2,2':5',2"terthiophene were dissolved in $20 \mathrm{~mL}$ of anhydrous THF, under dry nitrogen atmosphere. At $-78^{\circ} \mathrm{C}, 11.9 \mathrm{~mL}(19 \mathrm{mmol})$ of $n$-butyllithium (1.6 $\mathrm{M}$ hexane solution) were added to the solution. The temperature was allowed to rise until $0^{\circ} \mathrm{C}$ for $10 \mathrm{~min}$, and then, after cooling to $-78^{\circ} \mathrm{C}, 0.61 \mathrm{~g}(23.7 \mathrm{mmol})$ of sulfur was added. Again the system was warmed to room temperature and after $1 \mathrm{~h}$ cooled to $-78^{\circ} \mathrm{C}$. $4.99 \mathrm{~g}(19 \mathrm{mmol})$ of 5 -(2-bromoethyl)undecane dissolved in $65 \mathrm{~mL}$ of dry THF was slowly dropped to the solution. After $48 \mathrm{~h}$ of stirring at room temperature, the reaction mixture was quenched with water, extracted with $\mathrm{CH}_{2} \mathrm{Cl}_{2}$, and the recovered organic phases dried over $\mathrm{Na}_{2} \mathrm{SO}_{4}$. After solvent evaporation, the product was purified by chromatography on silica gel using $n$-heptane/ethyl acetate 9:1 as eluent. $3.69 \mathrm{~g}(7.98 \mathrm{mmol}$, yield $42 \%)$ of a viscous yellow liquid was recovered.

${ }^{1} \mathrm{H} \mathrm{NMR}\left(\mathrm{CDCl}_{3}\right): \delta=0.8\left(\mathrm{~m}, 6 \mathrm{H}, \mathrm{CH}_{3}\right) ; 1.0-1.7\left(\mathrm{~m}, 22 \mathrm{H}, \mathrm{CH}_{2}, \mathrm{CH}\right) ; 2.8$ (t, 2H, ArS$\mathrm{CH} 2-)$; 6.9-7.3 (m, 7H,aromatic $\mathrm{CH}$ ) ppm.

${ }^{13} \mathrm{C} \mathrm{NMR}\left(\mathrm{CDCl}_{3}\right): \delta=14.1\left(\mathrm{CH}_{3}\right) ; 22.7-29.7\left(\mathrm{CH}_{2}\right) ; 31.9(-\mathrm{CH} 2-\mathrm{CH} 2-\mathrm{S}) ; 36.9(-\mathrm{CH} 2-$ CH2-S);123.6 (terthiophene C5"); 123.7-127.8 (terthiophene C); 133.9 (terthiophene C5) $\mathrm{ppm}$.

FT-IR: 692 ( $\nu$ C-S); 790 ( $\mathrm{CC}-\mathrm{H}$ aromatic); 1580 ( $\nu$ aromatic ring); $2856\left(\mathrm{v}_{\mathrm{s}} \mathrm{CH}_{2}\right), 2926$ $\left(\nu_{\text {as }} \mathrm{CH}_{2}\right), 2956\left(\mathrm{~V}_{\text {as }} \mathrm{CH}_{3}\right), 3070$ (v aromatic $\left.\mathrm{CH}\right) \mathrm{cm}^{-1}$.

UV-vis: $\lambda_{\max }=373 \mathrm{~nm} ; \varepsilon=35950 \mathrm{~L} \cdot \mathrm{mol}^{-1} \cdot \mathrm{cm}^{-1}$. 
The preparation of 5"-thiooctadecyl-2,2':5',2"-terthiophene (2) was reported previously [6].

[1] Broer, A.; Van Haaren, J.A.M.M.; Van de Witte, P.; Bastiaansen, C.; Macromol. Symp. 2000, 154, 1.

[2] (a) Uznansky, P.; Kryszewski, M.; Thulstrup, E.W.; Eur. Polym. J. 1991, 27, 41.

(b) Advincula, R.C.; Fells, E.; Park, M.K.; Chem. Mater. 2001, 13, 2870.

[3] a) Raji, K.P. ; Pillai, C.K.S.; Synth. Met. 2000, 114, 27. (b) Carinhana, J.; Faez, R.; Nogueira, A.F.; De Paoli, M.A.; Synth. Met. 2001, 121, 1569.

[4] Miteva, T.; Minkova, L.; Magagnini, P.; Macromol. Chem. Phys. 1998, 199, 1519.

[5] Montali, A.; Palmans, A.R.A.; Englin, M; Weder, C.; Smith, P.; Trabesinger, W.; Renn, A.; Hecht, B; Wild, U.P.; Macromol. Symp. 2000, 154, 105.

[6] Tirelli, N; Amabile, S; Cellai, C; Pucci, A; Regoli, L; Ruggeri, G; Ciardelli, F; Macromolecules 2001, 34, 2129.

[7] Ciardelli, F; Cellai, C; Pucci, A; Regoli, L; Ruggeri, G; Tirelli, N.; Cardelli, C.; Polym. Adv. Technol. 2001, 12, 223.

[8] Englin, E.; Montali, A.; Palmans, A.R.A.; Tervoort T.; Smith, P.; Weber, C.; J. Mater. Chem. 1999, 9, 2221.

[9] Pucci, A.; Ruggeri, G.; Moretto, L.; Bronco, S.; Polym. Adv. Technol. 2002, in press.

[10] Carpita, A.; Rossi, R.; Tetrahedron 1985, 7, 1999.

[11] Ward, I.M.; "Mechanical Properties of Solid Polymers", $2^{\text {nd }}$ edition, Wiley, New York 1985.

[12] Ward, I.M.; Proc. Phys. Soc. 1962, 80, 1176.

[13] Dirix, Y.; Tervoort, T.A.; Bastiaansen C.W.M.; Lemstra, P.J.; J. Text. Inst. 1995, $86,314$.

[14] Michl, J.; Thulstrup, E.; "Spectroscopy with Polarized Light", VCH Publishers Inc., New York 1986.

[15] Dirix, Y.; Tervoort, T.A.; Bastiaansen C.W.M.; Macromolecules 1995, 28, 486.

[16] Phillips, P.S.; Chem. Rev. 1990, 90, 425.

[17] Palmans, A. R. A.; Eglin, M.; Montali, A.; Weder, C.; Smith, P.; Chem. Mater. 2000, 12, 472. 